\title{
PROTOTYPOWE ZROBOTYZOWANE GNIAZDO TECHNOLOGICZNE
}

\begin{abstract}
Przedstawiono koncepcję budowy stanowiska obróbczego zbudowanego z wykorzystaniem typowych elementów wykonawczych, które stanowi stół obrotowy z czterema gniazdami. Zespołami współpracującymi są: manipulator podający detale, urządzenie skrawające, moduł kontroli jakości wykonania, magazyn elementów gotowych. Szczegółowo opisano budowę, wewnętrzne urządzenia napędowe oraz chwytak manipulatora będącego oryginalną konstrukcją. Stanowisko technologiczne zostało zamodelowane za pomocą dwóch programów komputerowych: programu graficznego Solid Edge oraz modułu Simulink programu Matlab. Moduł Part programu Solid Edge umożliwia zamodelowanie elementów znormalizowanych wykorzystanych w konstrukcji stanowiska, a także projektowanych od podstaw jako oryginalne rozwiązania. Moduł Assembly służy do wykonania prototypu stanowiska roboczego i przeprowadzenia żądanych zmian położenia bądź zmian wymiarowych poszczególnych zespołów lub części. Przedstawiono szczegóły konstrukcyjne pozostałych zespołów oraz opisano cykl pracy stanowiska.
\end{abstract}

Słowa kluczowe: manipulator, moduł konstrukcyjny, moduł kontroli, moduł obróbki

\section{Wprowadzenie}

W ramach zleceń zewnętrznych w Katedrze Podstaw Konstrukcji Maszyn Politechniki Lubelskiej wykonano projekty stanowisk montażowych i obróbczych z wykorzystaniem stołu obrotowego [1] oraz urządzeń transportowych spokrewnionych z układnicami regałowymi [2]. Stanowiska technologiczne są zbudowane z typowych urządzeń zasilanych pneumatycznie. Struktura taka pozwala na rozbudowanie stanowiska, zastapienie wybranych podzespołów nowymi lub poprzez zmianę elementów wykonawczych przeprowadzenie innego rodzaju obróbki. Dodatkową zaletą takiego stanowiska jest szybkość i łatwość wymiany modułów. Umożliwia to skrócenie czasu i pracochłonności projektowania oraz wykonania poprzez wysoki stopień unifikacji i normalizacji elementów zespołów konstrukcji. Zmianom takim uległo stanowisko stanowiące stół obrotowy, na którym zachodzi proces frezowania otworu w przedmiocie obra-

\footnotetext{
${ }^{1}$ Autor do korespondencji/corresponding author: Aleksander Nieoczym, Politechnika Lubelska, ul. Nadbystrzycka 36, 20-618 Lublin, tel.: 603107 371, e-mail: a.nieoczym@pollub.pl
} 
bianym [1]. Podajnik grawitacyjny detali zastąpiono manipulatorem dostarczającym elementy obrabiane do gniazd.

\section{Konstrukcja manipulatora}

Transport detali z zewnętrznego zasobnika jest realizowany za pomocą manipulatora (rys. 1.). Do napędu członów czynnych ramion manipulatora wykorzystuje się napęd elektryczny, co zapewnia uproszczenie konstrukcji mechanizmów i wysoką dokładność pozycjonowania. Zastosowane w projekcie silniki do napędu członów manipulatora są serwonapędami, w skład których wchodzą przekładnie planetarne oraz synchroniczne serwosilniki prądu przemiennego z magnesami trwałymi, pozwalającymi na uzyskanie relatywnie dużej wartości momentu obrotowego przy stosunkowo małym momencie bezwładności silnika. Dzięki wbudowanym enkoderom absolutnym pracującym w pętli sprężenia zwrotnego można uzyskać powtarzalność pozycjonowania z dokładnością do $0,01 \mathrm{~mm}$. Do ich rozruchu oraz regulacji prędkości konieczne jest stosowanie serwofalowników. Napęd mechanizmu chwytaka jest realizowany przez zespół

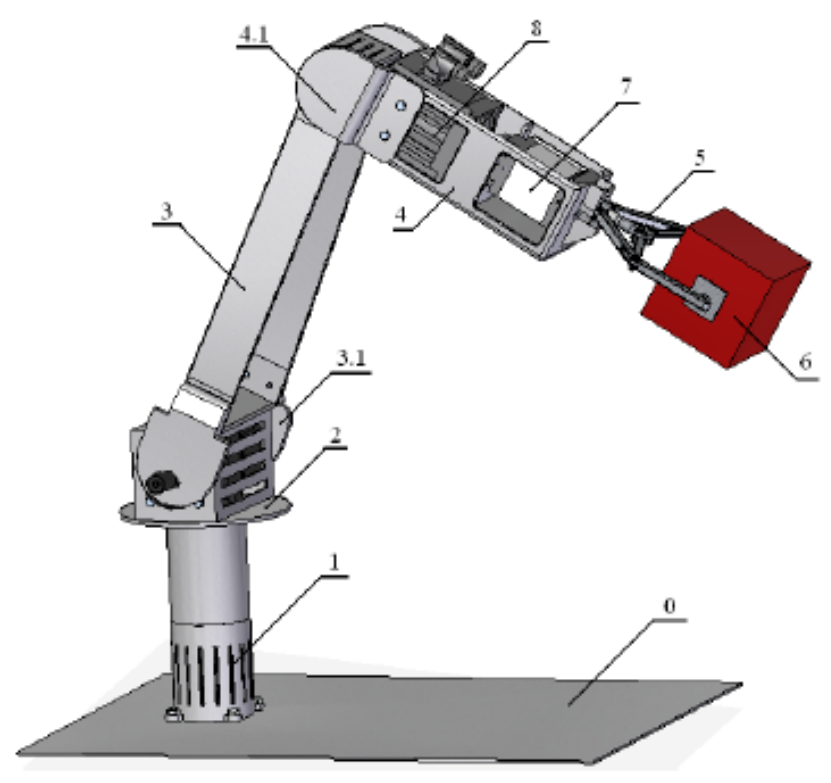

Rys. 1. Manipulator: 0 - podstawa, 1 - łącznik podstawy z obrotnicą, 2 - obrotnica, 3 - ramię, 3.1 - łapka ramienia, 4 - przedramię, 4.1 - przegub, 5 - chwytak, 6 - przenoszony ładunek, 7 - siłownik, 8 - silnik chwytaka

Fig. 1. Manipulator: 0 - base, 1 - connector of the base with turn-table, 2 - turn-table, 3 - arm, 3.1 - little arm of shoulder, 4 - forearm, 4.1 - joint, 5 - gripper, 6 - moving cargo, 7 servo, 8 - engine of the gripper 
Rys. 2. Przedramię manipulatora z silnikiem, chwytakiem i ładunkiem

Fig. 2. Forearm of the manipulator with the engine, the gripper and the cargo

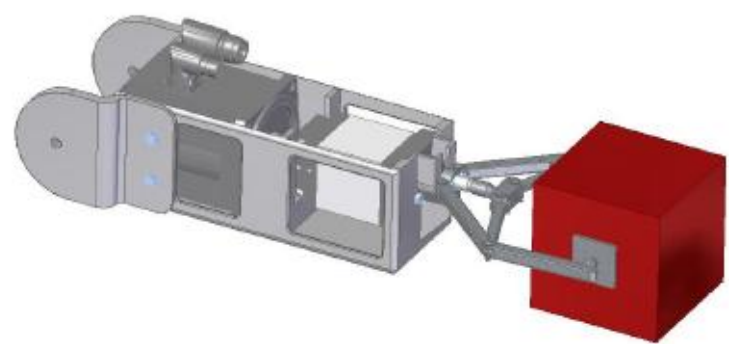

silnik-siłownik składający się z siłownika mechanicznego RHT/K60A oraz serwomotoru EZ401U (rys. 2.). Zespół został wbudowany w przedramię jednostki monolitycznej tak, że oś zespołu ma kierunek siły wzdłużnej przedramienia. Sztywne osadzenie zespołu napędowego jest możliwe przez odpowiednie wyprofilowanie wnętrza przedramienia i mocowanie za pomocą śrub. W ramię jednostki wbudowano silnik umożliwiający ruch przedramienia (serwonapęd P222_0350 ED212U firmy Stoeber). Serwonapęd został wbudowany w końcową część ramienia $\mathrm{w}$ taki sposób, że oś silnika jest jednocześnie osią obrotu pary kinematycznej ramię-przedramię. Wał silnika jest połączony za pomocą wpustu z przedramieniem. Równomierny rozkład obciążenia w rozważanej parze kinematycznej zapewnia węzeł łożyskowy przenoszący cześć momentu gnącego. Chwytak, tj. płaska końcówka robocza ramienia manipulatora, został zaprojektowany jako płaski mechanizm dźwigniowy (rys. 3.). Dwa symetryczne ramiona, których końce są przyłączone przegubowo za pomocą sworzni do pierścienia mocującego. Pierścień mocujący jest przytwierdzony sztywno do przedramienia jednostki monolitycznej manipulatora. Ramiona chwytaka mają kształt wygiętych prętów. W miejscu wygięcia są one połączone przegubowo (za pomocą sworzni) z identycznymi łącznikami, które z kolei są połączone przegubowo z dwuczęściową oprawą. Ramiona są zakończone szczękami osadzonymi przegubowo (przeguby sferyczne), co pozwala na lepsze dopasowanie powierzchni szczęk do powierzchni podnoszonego ładunku. Zastosowanie przegubu kulistego w połączeniu kulka przegubu-opraw kulki ma na celu wyeliminowanie przenoszenia momentu gnącego na tłoczysko siłownika.

Rys. 3. Mechanizm chwytaka manipulatora

Fig. 3. Mechanism of the gripper of the manipulator

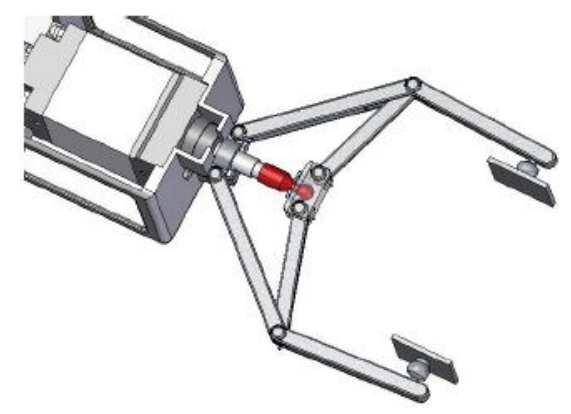




\section{Zasada działania stanowiska}

Transport przedmiotu obrabianego następuje w wyniku przemieszczenia go za pomocą manipulatora do pierwszego gniazda na stole obrotowym, na którym zostanie przeprowadzona obróbka frezowania (rys. 4a). Po umieszczeniu przedmiotu obrabianego w gnieździe obróbkowym następuje obrót stołu obrotowego DHTG-220-4-A, który jest wyposażony w czujniki położenia SIEN-M8B-PS-S-L, o $90^{\circ}$. W drugim etapie przedmiot obrabiany zostaje dociśnięty do tylniej ściany gniazda obróbkowego. Ruch obrotowy freza nadaje silnik, który jest sterowany cyfrowo. Po wykonaniu otworu w przedmiocie obrabianym i wycofaniu się siłownika $\mathrm{z}$ frezarką następuje obrót stołu o kolejne $90^{\circ}$. Podczas kontroli (rys. 4b) przedmiot obrabiany zostaje unieruchomiony przez docisk. Następnie jest wykonywany pomiar głębokości otworu. Siłownik DNCB-32-40-PPV-A
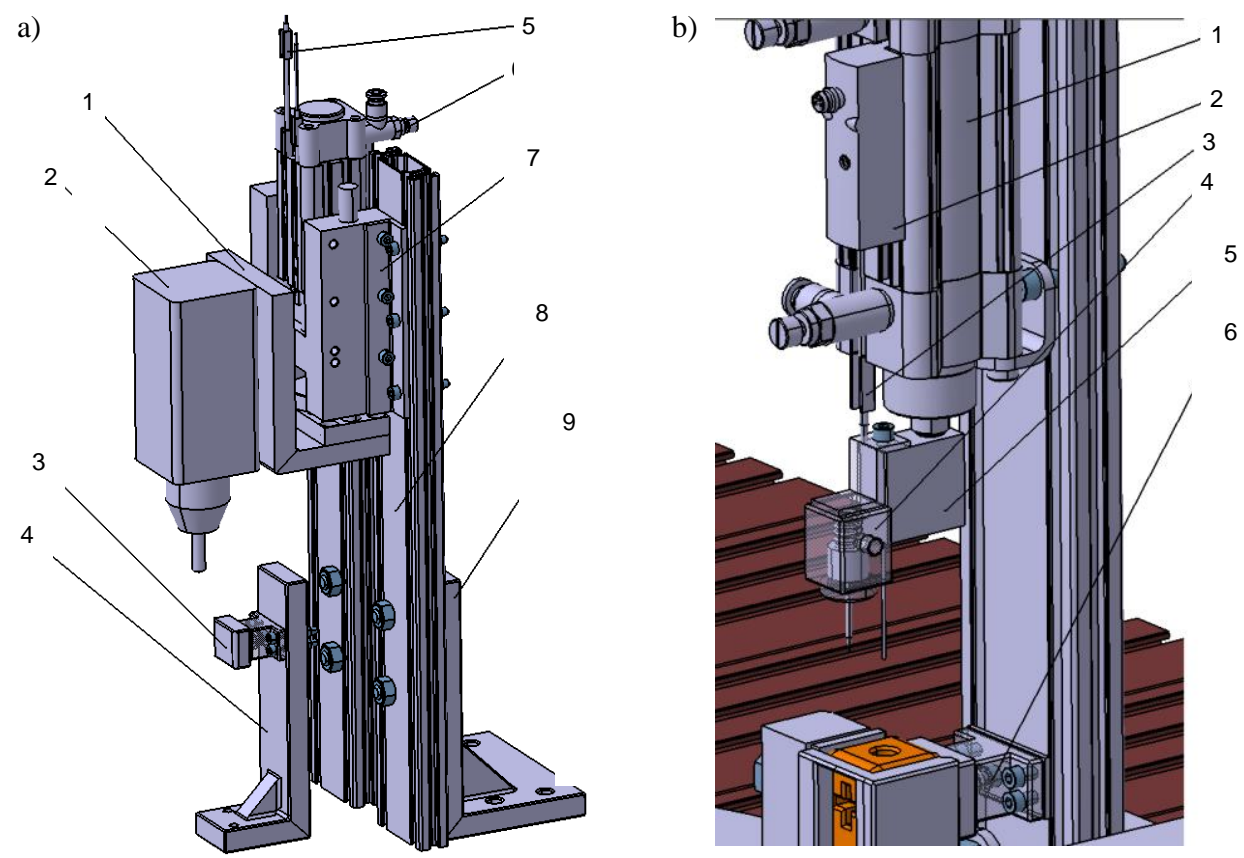

кys. 4. Elementy składowe stanowiska: a) zespół obróbczy; 1 - uchwyt frezarki, 2 - frezarka, 3 - docisk, 4 - mocowanie docisku, 5 - wyłącznik zbliżeniowy, 6 - zawór zwrotno-dławiący, 7 - kątownik do mocowania jednostki prowadzącej, 8 - profil aluminiowy, 9 - mocowanie profili aluminiowych, b) przedmiot obrabiany w gnieździe kontroli; 1 - siłownik, 2 - nadajnik położenia, 3 - wyłącznik zbliżeniowy, 4 - czujnik materiału, 5 - głębokościomierz, 6 - docisk

Fig. 4. Elements of the stand: a) processing unit; 1 - fixture of the milling machine, 2 - milling machine, 3 - clamping device, 4 - clamping of the clamping device, 5 - proximity switch, 6 - throttle-non-return valve, 7 - square to clamping the guide unit, 8 - aluminium profile, 9 - clamping of aluminium profiles, b) object worked in the centre of the control; 1 - servomotor, 2 - transmitter of the position, 3 - proximity switch, 4 - sensor of material, $5-$ depth gauge, 6 - clamp 
dwustronnego działania wyposażony w nadajnik położenia SMAT-8E-S50-IU-M8 oraz wyłącznik zbliżeniowy SME-8M-DS-24V-K-2,5-OE wykonuje ruch posuwowy. Głębokościomierz mierzy głębokość otworu za pomocą nadajnika położenia SMAT-8E-S50-IU-M8. Po sprawdzeniu głębokości otworu siłownik z głębokościomierzem wraca do pozycji początkowej. Następnie stół obrotowy DHTG-220-4-A wykonuje obrót o kolejne $90^{\circ}$.

W ostatnim etapie - sortowaniu następuje transport przedmiotu obrabianego przez siłownik DNC-32-40-PPV-A dwustronnego działania do magazynu (rys. 5.), który jest umieszczony na napędzie liniowym EGC-7-500-TB-KF-30H-GK. Magazyn składa się z trzech kieszeni. W zależności od rezultatów kontroli głębokości przedmiot obrabiany jest transportowany do odpowiedniej kieszeni. W pierwszej i drugiej kieszeni zostaje umieszczony przedmiot obrabiany, w którym otwór został wykonany prawidłowo, natomiast w trzeciej kieszeni - przedmiot obrabiany, w którym otwór został wykonany nieprawidłowo.

Rys. 5. Elementy składowe procesu sortowania: 1 - wyłącznik zbliżeniowy, 2 - siłownik, 3 - stół obrotowy, 4 - magazyn, 5 napęd liniowy

Fig. 5. Elements of the process of the sorting: 1 - proximity switch, 2 - servo-motor, 3 - turntable, 4 - magazine, 5 - linear propulsion

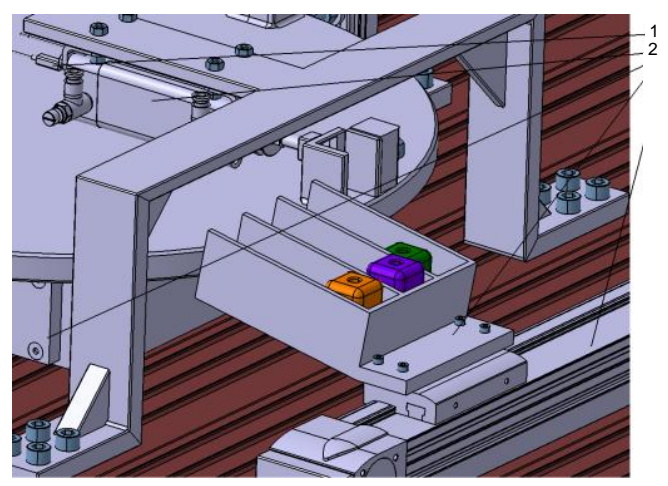

\section{Układ sterowania}

Funkcję sterowania elektrycznego przyjmuje sterownik logiczny PLC Simatic S7-300 firmy Siemens. Jest on sprzężony ze sterownikiem napędu liniowego CMMS-ST-C8-7 oraz wyspa zaworowa MPA-MPM-VI 32E-MPM+GD 32P-SFL-R-MBBSVBIU-4MKJ+3Z. Sterownik napędu liniowego odbiera sygnały z pięciu wyłączników zbliżeniowych SIES-8M-PO-24V-K-7,5-OE, po czym przekazuje je do głównego sterownika logicznego PLC, którym jest Simatic S7-300, gdzie są dalej przetwarzane. Sterownik Simatic S7-300 otrzymuje sygnały na wejściu od wyłączników zbliżeniowych SME-8M-DS-24V-K-2,5-OE, nadajnika położenia SMAT-8E-S50-IU-M8, wyłączników zbliżeniowych SIEN-M8B-PS-S-L oraz specjalnie do tego celu zaprojektowanego czujnika materiału. Na wyjściu ze sterownika logicznego PLC Simatic S7-300 znajduje się dziesięć elektrozaworów jednocewkowych, które sterują medium roboczym, jakim jest sprężone powietrze. Sprężone powietrze jest doprowadzane przez sprężarkę do siłowników DNC-32-40-PPV-A dwustronnego działania oraz stołu 
obrotowego DHTG-220-4-A, silnika wiertarki i napędu liniowego. Rysunek 6. przedstawia schemat układu sterowania elektronicznego.

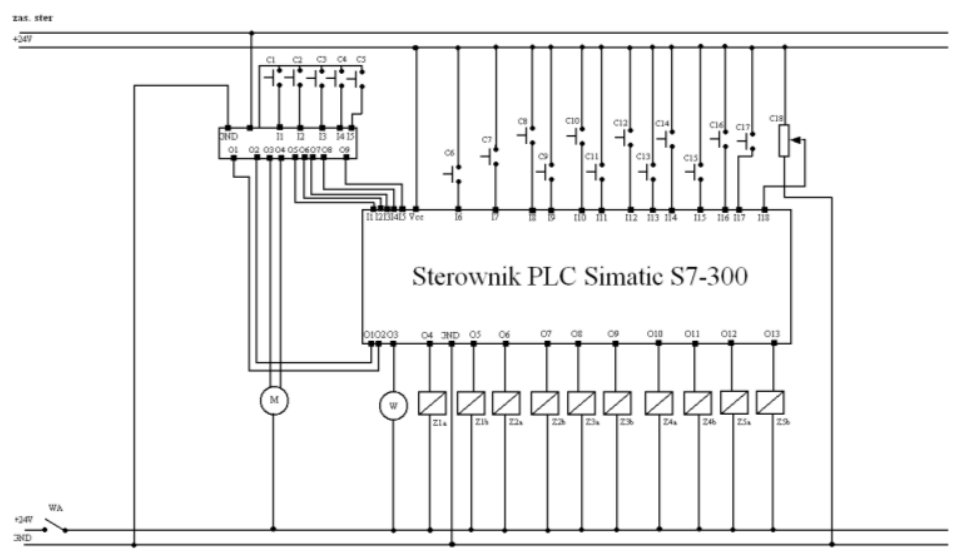

Rys. 6. Schemat układu sterowania elektronicznego

Fig. 6. Scheme of the electronic control system

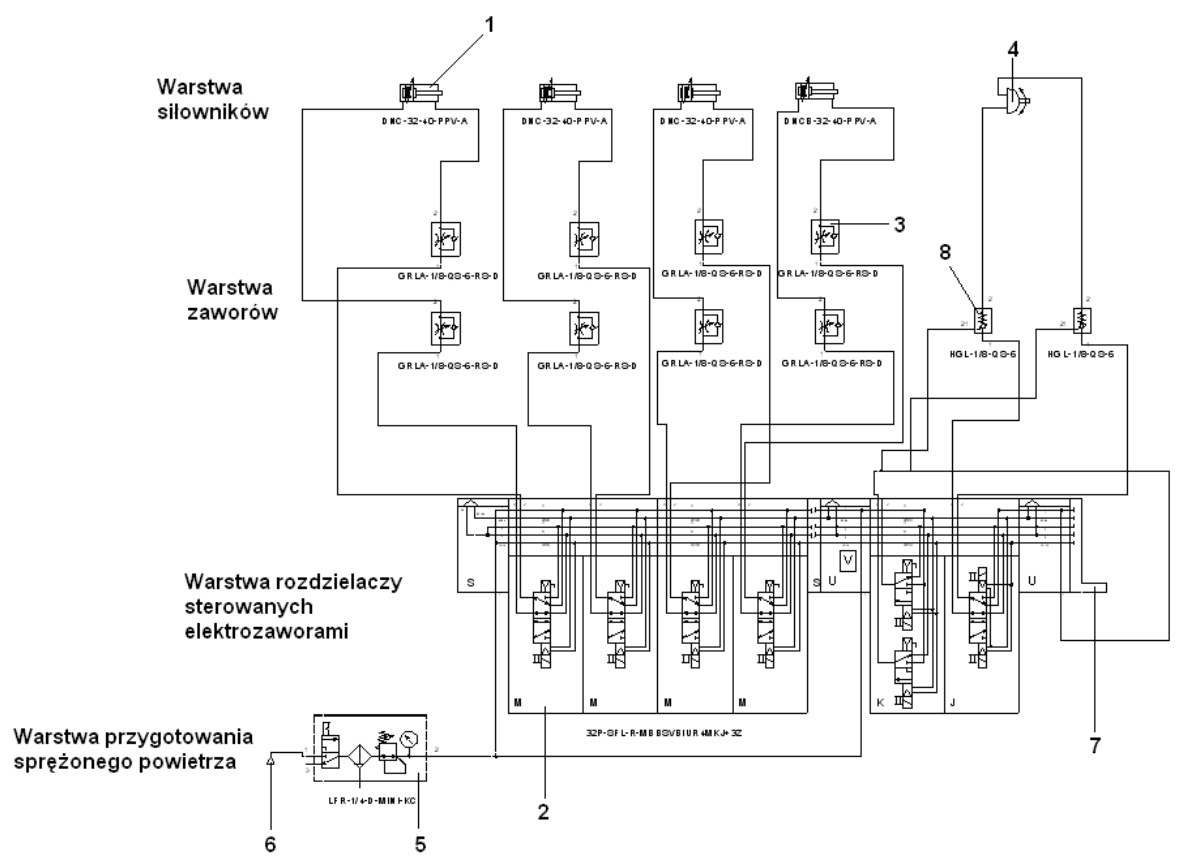

Rys. 7. Schemat sterowania pneumatycznego: 1 - siłownik, 2 - elektrozawór, 3 - zawór zwrotno-dławiący, 4 - stół obrotowy, 5 - zespół przygotowania sprężonego powietrza, 6 - sprężarka, 7 - wyspa zaworów, 8 - zawór zwrotny

Fig. 7. Scheme of air control: 1 - servo-motor, 2 - solenoid valve, 3 - throttle - non-return valve, 4 - turntable, 5 - unit of preparing the compressed air, 6 - compressor, 7 - island of valves, 8 - non-return valve 
Większość elementów wykonawczych wykorzystanych w projekcie stanowią elementy pneumatyczne. Do sterowania elementami pneumatycznymi w mechatronicznym systemie produkcyjnym została użyta wyspa zaworowa MPA-MPM-VI 32E-MPM+GD 32P-SFL-R-MBBSVBIU-4MKJ+3Z. Sprężone powietrze ze sprężarki trafia do zespołu przygotowania sprężonego powietrza. $\mathrm{W}$ zespole przygotowania sprężonego powietrza jest ono oczyszczane $\mathrm{z}$ zanieczyszczeń i dalej trafia do wyspy zaworowej, która za pomocą elektrozaworów rozdziela medium robocze, jakim jest powietrze, do wszystkich elementów wykonawczych układu pneumatycznego mechatronicznego systemu produkcyjnego. Każdym siłownikiem dwustronnego działania steruje elektrozawór, z którego powietrze poprzez dwa zawory zwrotno-dławiące trafia do komory siłownika. Wyspa zaworowa jest podłączona do sterownika logicznego PLC Simatic S7-300 firmy Siemens, który „czuwa” nad poprawnym przebiegiem procesu produkcyjnego.

$\mathrm{Na}$ rysunku 7. przedstawiono schemat sterowania pneumatycznego. $\mathrm{Na}$ schemacie występują symbole siłowników, zaworów zwrotno-dławiących, zaworów zwrotnych, elektrozaworów znajdujących się w wyspie zaworowej, stołu obrotowego, zespołu przygotowania sprężonego powietrza i sprężarki, która dostarcza medium robocze w postaci sprężonego powietrza.

\section{Podsumowanie}

Opisane stanowisko technologiczne zostało zamodelowane z wykorzystaniem dwóch programów komputerowych: graficznego Solid Edge oraz modułu Simulink programu MathLab. Moduł Part programu Solid Edge umożliwia zamodelowanie elementów znormalizowanych wykorzystanych w konstrukcji stanowiska, a także projektowanych od podstaw jako oryginalne rozwiązania. Moduł Assembly służy do wykonania prototypu stanowiska roboczego i przeprowadzenia żądanych zmian położenia bądź zmian wymiarowych poszczególnych zespołów lub części. W dalszej kolejności jest przeprowadzana symulacja pracy łącznie $\mathrm{z}$ analizą kolizji. Opisane narzędzia wraz ze stworzonymi bazami podzespołów umożliwiają szybkie prototypowanie oraz możliwość przekonstruowania stanowiska pod indywidualne zamówienie.

\section{Literatura}

1. Nieoczym A.: Modułowe stanowisko obróbcze. Technologia i Automatyzacja Montażu, nr 3, 2010.

2. Nieoczym A.: Pionowy krzyżowy układ transportowy stanowiska roboczego. Logistyka, nr 6, 2010. 


\title{
PROTOTYPE ROBOTIZED TECHNOLOGICAL CENTRE
}

\begin{abstract}
A bstract
The article presents the concept of building the machining stand using a typical actuator. It is based on a turntable with four slots. Collaborating teams are: the manipulator giving details, the cutting device, quality control module and the storage of finished elements. The construction, inside driving devices and the gripper of the manipulator being an original structure have been described in detail. The technological stand was modelled using two computer programs: the graphical program SolidEdge and the Simulink environment integrated with Matlab. The Part module of Solid Edge software allows to model standard elements applied in the stand construction and also in the design of original solutions of elements. The Assembly module allows to make the prototype of a work-stand and to perform required dimensional modifications of particular assemblies and parts. Structural details of remaining teams as well as a working cycle of the stand have been presented.
\end{abstract}

Keywords: manipulator, structural module, module of the control, module of processing

DOI: $10.7862 / \mathrm{rm} .2013 .4$

Otrzymano/received: 25.02 .2013

Zaakceptowano/accepted: 17.04.2013 